\title{
Logística integrada em indústria madeireira de Santa Catarina
}

Franciane Luiza Salamoni Pioli

Mestrado em Ciências Contábeis pela Universidade Regional de Blumenau - FURB Rua Sete de Setembro, 169. (SENAC). Caçador/SC. CEP: 89500-000 E-mail: fransalamoni@gegnet.com.br

Ilse Maria Beuren Doutorado em Controladoria e Contabilidade pela Universidade de São Paulo - USP Professora da Universidade Regional de Blumenau - FURB Rua Antonio Veiga, 104. (FURB/PPGCC). Blumenau/SC. CEP: 89012-900

E-mail: ilse@furb.br

\section{RESUMO}

A logística integrada possui relevância na gestão da indústria madeireira, porque busca aproximar fornecedores-empresa-clientes para melhorar a qualidade do seu produto, sem necessariamente aumentar seus custos, além de alcançar maior eficiência, produtividade e flexibilidade. Neste sentido, o presente artigo objetiva descrever a logística integrada em uma indústria madeireira de Santa Catarina. Para tanto, realizouse uma pesquisa exploratória, por meio de estudo de caso, utilizando-se de pesquisa documental e técnica de observação, com abordagem qualitativa dos dados. Inicialmente, faz-se uma incursão teórica na logística integrada e na cadeia de suprimentos; em seguida descreve-se a implantação da logística integrada na indústria madeireira. Os resultados da pesquisa mostram que a logística integrada está valorizando não só o produto final, mas também a matéria-prima, que muitas vezes era desconsiderada no quesito qualidade. Embora a logística integrada na indústria madeireira pesquisada esteja sendo implantada lentamente, já apresenta resultados interessantes. Ela contribui para conferir maior qualidade ao produto fabricado, devido ao fato de existir integração efetiva entre todos os setores e os fornecedores tenderem a primar pela qualidade da matéria-prima. Também está proporcionando à cadeia global da indústria madeireira a redução de custos e uma maior agilidade no atendimento, além de maior satisfação aos clientes ao longo do processo.

Palavras-chave: Logística integrada. Cadeia de suprimentos. Indústria madeireira. 


\section{ABSTRACT}

Integrated logistics is relevant to the management of the lumber industry because it seek to bring suppliers, clients and companies closer together, in order to improve the quality of its product without necessarily increasing costs and achieve greater efficiency, productivity and flexibility. In this sense, the objective of the present article is to describe the logistics integrated into the Santa Catarina lumber industry. To do so, exploratory research was made, by means of a case study of a lumber company, using document research and observations technique and applying a qualitative approach to the data. The first step was to undertake a review of integrated logistics theory and the supply chain. This was followed by a description of the implantation of integrated logistics in the lumber company. Research results show that integrated logistics is valuable not only in the final product but also in raw material, which often not considered in the question of quality. It was concluded that integrated logistics in the lumber company researched is being implanted slowly, although interesting results have already appeared. It contributed to conferring greater quality to the product it makes, due to the fact that there is effective integration between every sector and that suppliers tend to lead in the quality of raw material. This is also enabling the global chain of the lumber industry to reduce costs and achieve greater agility in serving clients, besides the greater client satisfaction during the course of the process.

Key Words: Integrated logistics. Supply chain. Lumber company.

\section{INTRODUÇÃO}

As transformações ocorridas nos últimos anos nos aspectos mercadológicos, econômicos e sociais, levaram à mudanças no comportamento do consumidor, que se tornou mais exigente quanto à qualidade e preço dos bens e serviços que adquire. De um lado, estão os consumidores que esperam variedade e qualidade maior de produtos, sem aumentar os preços. De outro lado, estão as pressões da concorrência para aumentar sua fatia de mercado, exigindo redução dos custos para assegurar a continuidade da empresa no mercado.

Com o aumento da competição entre as empresas nos diferentes setores de atuação, torna-se cada vez mais relevante a utilização de instrumentos gerenciais que possam auxiliar na tomada de decisão dos gestores. A logística pode ser entendida como uma forma de aumentar o grau de eficiência empresarial, uma vez que, através 
da integração entre fabricante, fornecedor e consumidor final, o processo se torna mais ágil, seguro, econômico e competitivo.

A missão da logística é estar com o bem ou serviço no lugar e tempo certo, nas condições desejadas, sempre contribuindo para a melhoria contínua da empresa. Isto requer o envolvimento de diversos agentes econômicos, internos e externos à empresa, surgindo assim a integração das atividades destes agentes, denominada de logística integrada. Verol e Dalto (2007) citam que um nível elevado de estoques pode ser um sintoma da falta de planejamento integrado, da não colaboração ao longo da cadeia de suprimentos, bem como fruto de precária utilização de ferramentas e sistemas que contribuem para esta integração.

A logística integrada busca integrar não só fornecedores-empresa-clientes, mas dentro da empresa todos os setores de produção. Ching (1999, p. 66) adverte que uma empresa somente poderá obter vantagens competitivas "por meio do aumento de produtividade, diferenciação do produto e níveis altos de serviço ao cliente. Esse processo não pode inserir-se exclusivamente nos limites da empresa, mas deve [...] estender-se a todas as partes envolvidas fora da empresa".

A logística integrada intenta contribuir para minimizar desperdícios na produção e distribuição de produtos, como falta de matéria-prima, gargalos na produção, atraso na entrega do produto final. De acordo com Hoek e Harrison (2003), existem cinco maneiras de competir por meio da logística: qualidade, velocidade, tempestividade, flexibilidade e custo. $\mathrm{Na}$ indústria madeireira, segmento específico deste estudo, a logística integrada também precisa estar atenta a esses focos de competição.

Nesta perspectiva, este artigo tem como objetivo descrever a logística integrada em uma indústria madeireira de Santa Catarina. A relevância do estudo está na abordagem de um instrumento de gestão que pode contribuir na promoção da eficiência da empresa em si e de toda a sua cadeia de valor. Também possui relevância na medida em que coteja o conceito de logística integrada com sua aplicação em uma empresa, podendo averiguar sua aplicação por meio de uma pesquisa empírica.

$\mathrm{O}$ artigo inicia com elementos da introdução do trabalho, particularmente na contextualização do tema e no objetivo do estudo. Em seguida faz uma incursão teórica 
na logística integrada e na cadeia de suprimentos. Na seqüência, evidencia o método e os procedimentos metodológicos aplicados na pesquisa, e depois descreve a aplicação da logística integrada na indústria madeireira objeto de estudo, além de apresentar a conclusão do estudo realizado.

\section{LOGÍSTICA INTEGRADA}

A competência administrativa se torna a cada dia mais importante para que a empresa consiga manter-se atuando no mercado competitivo no qual está inserida. A abrangência do gerenciamento vai desde a compra ou produção da matéria-prima até a entrega do produto final ao cliente. Nesta perspectiva, a logística não pode mais ser vista apenas como uma atividade relacionada ao transporte. Também não deve ser entendida apenas como distribuição física de produtos aos clientes.

A logística pode ser concebida como uma atividade de suporte em todos os campos, para incrementar e solidificar o resultado dos negócios das empresas. Está voltada à industrialização da matéria-prima, fabricação e comercialização do produto e prestação de serviços relacionados. A logística abrange o processo de planejamento e controle da matéria-prima, dos estoques em andamento e dos produtos acabados, considerando a cadeia completa fornecedores-empresa-clientes. Procura também subsidiar os gestores com informações, desde o início do processo de produção dos bens e serviços, ou seja, do seu ponto de origem, até o cliente final, com o objetivo de atender às exigências do cliente.

Preocupa-se com a oferta dos bens e serviços por parte das empresas aos clientes, no tempo certo e no lugar desejado. Silva e Villar (2007) salientam que um elemento adicional vem em atendimento a essa necessidade, ou seja, a busca de agregação de valor aos produtos/serviços em decorrência da crescente exigência por parte dos clientes, ou diante de uma ação de diferenciação da concorrência.

Denominando a logística de logística empresarial, Ballou (1993, p.24) entende que ela se consubstancia de 
todas as atividades de movimentação e armazenagem, que facilitam o fluxo de produtos desde o ponto de aquisição da matéria-prima até o ponto de consumo final. Assim como dos fluxos de informações que colocam os produtos em movimento, com o propósito de providenciar níveis de serviços adequados aos clientes a um custo razoável.

A logística busca atender primeiramente atividades primárias (transportes, manutenção de estoques e processamento de pedidos), pois são elas que contribuem com a maior parcela de custo total da logística e também pela sua importância para a coordenação e o cumprimento da tarefa logística. Em segundo plano busca atender as atividades de apoio (armazenagem, manuseio de materiais, embalagem de proteção, obtenção, programação de produtos e manutenção de informação), também conhecidas como atividades adicionais (CHING, 1999).

As empresas cada vez mais vêm buscando capacitação logística que permita a entrega rápida e confiável de bens e serviços, incorporando flexibilidade e tempestividade para operar em ambientes dinâmicos. Essa capacitação vem sendo incorporada como um elemento-chave nas estratégias de marketing. Dornier et al. (2000, p. 39) alertam que para satisfazer às demandas do mercado, a organização deve se estruturar de acordo com alguns ou todos os fluxos físicos que seguem:

a) Matérias-primas, do ponto de estocagem da fonte original até a entrega para o cliente.

b) Produtos semi-acabados, vindos de unidades de manufatura próprias ou de fábricas ou armazéns dos fornecedores.

c) Ferramentas ou máquinas, de uma unidade de manufatura para outra.

d) Produtos acabados entre plantas, armazéns próprios, armazéns dos clientes, ou armazéns pertencentes a empresas de serviços logísticos.

f) Itens consumíveis e peças de reposição, de armazéns para os veículos dos técnicos de reparos, ou para as unidades dos clientes onde os equipamentos estão instalados.

g) Produtos e peças a serem reparados, da unidade do cliente para o local de reparo/recuperação.

h) Equipamentos de suporte de vendas, como estandes e displays, quadros de propaganda, literatura, e outros, das empresas para os agentes apropriados. 
i) Embalagens vazias retornadas, dos pontos de entrega para os pontos de carregamento.

j) Produtos vendidos ou componentes devolvidos, dos pontos de entrega para o ponto inicial de armazenagem ou manufatura (fluxo reverso).

I) Produtos usados/consumidos a serem reciclados, recauchutados, reutilizados ou postos à disposição (fluxo reverso).

A logística integrada remete a uma visão mais ampla, que envolve fornecedor, empresa e clientes, compreendendo tanto o suprimento físico de matéria-prima como a distribuição física do produto. Segundo Ballou (1993), está associada ao estudo e administração de fluxos de bens e serviços, juntamente com a informação que os movimenta.

Sobre a informação relacionada aos fluxos de bens e serviços, Ladeira e Oliveira (2007) dão destaque às novas tecnologias de informação (TI), entendendo-as como decisivas para atender os objetivos de integração de processos e atividades, bem como para a administração da complexidade nas cadeias de suprimento que são cada vez mais orientadas pela demanda.

De acordo com Christopher (1997), a logística integrada busca aproximar a cadeia de suprimentos, desde matéria-prima até o ponto de consumo, por meio do planejamento e coordenação do fluxo de materiais da fonte até o usuário (cliente) como um sistema integrado. Com a logística integrada busca-se um trabalho conjunto na promoção da qualidade, seja no produto que se está vendendo, seja no atendimento que se está recebendo, formando uma rede.

No entanto, as ligações significativas na rede precisam ser identificadas. Slack et al. (1996, p. 182) advertem que a sua análise "provavelmente mostrará que todos os elos da rede contribuem com alguma coisa, mas as contribuições não serão igualmente significativas. Cada parte da rede pode compreender o que é importante, mas nem todas as partes estão em posição de poder ajudar".

Sobre a finalidade da integração da cadeia logística, Novaes (2004, p. 37) explica que a moderna logística procura incorporar:

a) Prazos previamente acertados e cumpridos integralmente, ao longo de toda a cadeia de suprimentos; 
b) Integração efetiva e sistêmica entre todos os setores da empresa;

c) Integração efetiva e estreita (parcerias) com fornecedores e clientes;

d) Busca da otimização global, envolvendo a racionalização dos processos e a redução de custos em toda a cadeia de suprimentos;

e) Satisfação plena do cliente, mantendo nível de serviço preestabelecido e adequado.

No entanto, os resultados dos processos logísticos precisam ser mensurados e quantificados, bem como de ações orientadas à sua melhoria permanente (BOWERSOX; CLOSS: COOPER 2006). Além da influência do processo de planejamento e controle dos sistemas logísticos e das características do produto e da demanda, Chopra e Meindl (2003) citam também a dinâmica dos mercados concorrentes, uma vez que alterações nos padrões de consumo dos clientes influenciam a oferta de valor logístico dos fornecedores.

Infere-se do exposto que a logística integrada precisa aproximar clientes e fornecedores à empresa, buscando o envolvimento de todos nos mesmos objetivos, que no passado eram dispersos ao longo da cadeia de valor. Esta aproximação pode proporcionar maior competitividade individual e conjunta aos integrantes da cadeia de valor.

\section{CADEIA DE SUPRIMENTOS}

A cadeia de suprimentos (supply chain) tem como parte do processo a logística. Segundo a maior organização profissional de logística, a Council of Logistics Management - CLM (1970), citada por Nohara e Acevedo (2005), esta é a parte do processo da cadeia de suprimentos que prevê o planejamento, implementação e controle do fluxo e estocagem de bens, serviços e informações relacionadas, desde o ponto de origem até o ponto de consumo, objetivando atender aos consumidores.

A logística fundamenta-se em um sistema de gestão que não visa só o controle físico da empresa e de seus setores, mas também um controle econômico detalhado dos mesmos. Ballou (1993, p. 17) explica que a logística "estuda como a administração 
pode prover melhor nível de rentabilidade nos serviços de distribuição aos clientes e consumidores, através de planejamento, organização e controles efetivos para as atividades de movimentação e armazenagem que visam facilitar o fluxo de produtos".

Christopher (1997, p. 21) menciona que para as empresas de hoje alcançarem no futuro uma posição de vantagem competitiva contínua, deverão ter "integradores orientados para a obtenção de sucesso no mercado, baseado em sistemas de gerenciamento de operações e entregas". Este é o diferencial que as empresas buscam na logística, enquanto elemento da cadeia de suprimentos. Chopra e Meindl (2003, p. 3) afirmam que

uma cadeia de suprimento engloba todos os estágios envolvidos, direta ou indiretamente, no atendimento de um pedido de um cliente. A cadeia de suprimento não inclui apenas fabricantes e fornecedores, mas também transportadoras, depósitos, varejistas e os próprios clientes.

Em uma cadeia de suprimentos cada elo requer cooperação dos outros, seja do fornecedor para a empresa, seja do cliente para e empresa e vice-versa. Christopher (1997, p. 13) afirma que "a cadeia de suprimentos representa uma rede de organizações, através de ligações nos dois sentidos, dos diferentes processos a atividades que produzem valor na forma de produtos e serviços que são colocados nas mãos do consumidor final".

De acordo com Pires et al. (2001, apud PIRES, 2004, p. 48), "uma supply chain é uma rede de companhias autônomas, ou semi-autônomas, que são efetivamente responsáveis pela obtenção, produção e liberação de um determinado produto e/ou serviço ao cliente final". Slack et al. (1996, p. 178) destacam que "nenhuma operação produtiva ou parte dela, existe isoladamente. Todas as operações fazem parte de uma rede maior, interconectadas com outras operações. Esta rede inclui fornecedores e clientes. Também inclui fornecedores dos fornecedores e clientes dos clientes e assim por diante".

Lamming et al. (2000, apud PIRES 2004, p. 52) sugerem "que o uso de rede de suprimentos (supply networks) seria mais apropriado, mas reconhecem que o termo 
supply chain tornou-se de fato muito popular". Segundo os autores citados, "a expressão supply chain é muito simplista, linear e unidirecional, enquanto que o termo supply network descreve as ligações laterais, os loops reversos, as trocas em duas direções e posiciona a empresa focal como ponto de referência". A Figura 1 revela a diferença preconizada entre supply chain e supply network.

Harland (1996) caracteriza a cadeia (chain) como sendo uma estrutura linear, sem ligações laterais e variações, seja de fornecedores ou clientes. Por sua vez, em redes (networks) a empresa continua sendo o ponto de referência, mas as ligações são laterais, pois há uma troca entre fornecedor/empresa e empresa/cliente.
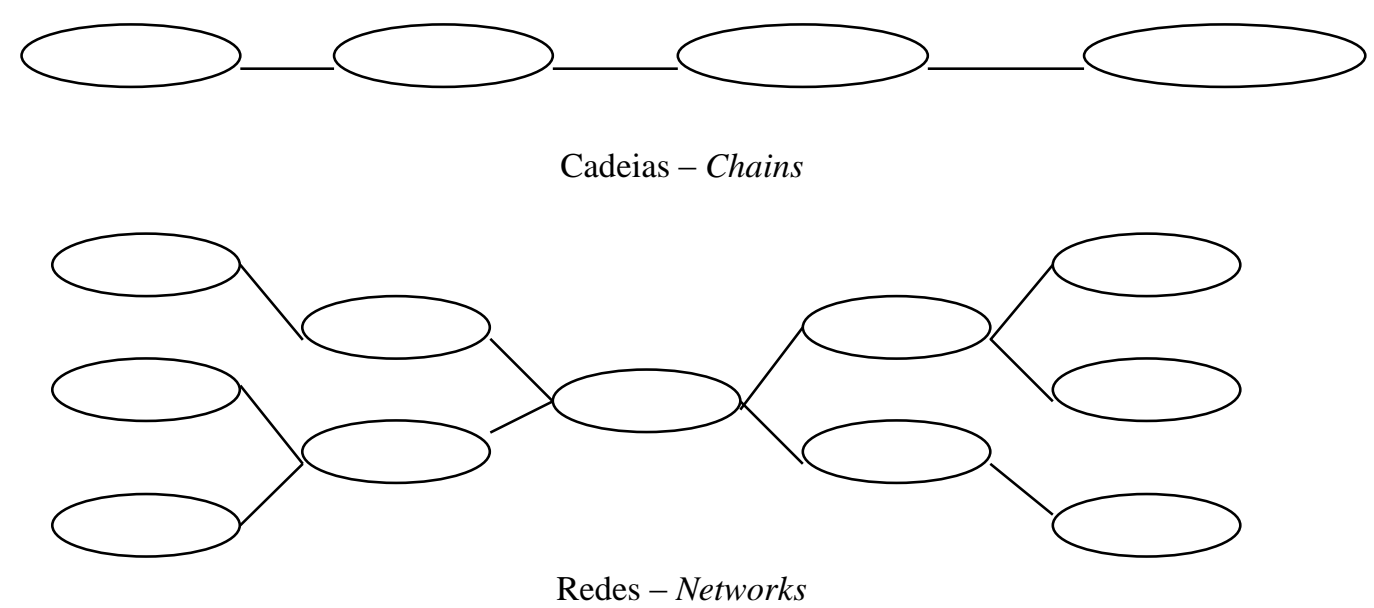

Figura 1 - Cadeias (Chains) e Redes (Networks)

Fonte: Harland (1996, apud PIRES, 2004, p. 53)

Slack (1993, p. 155) classifica as redes de suprimentos em três níveis: rede total, rede imediata e rede interna. Define a rede interna como aquela composta pelos fluxos de informações entre departamentos, células ou setores de operações internas à própria empresa. De outro lado, a rede imediata é formada pela relação entre fornecedores e consumidores, como também fornecedora e consumidora de outras empresas. Por fim, a rede total é composta por todas as preocupações imediatas para a operação.

$\mathrm{Na}$ Figura 2 apresentam-se as funções das redes de suprimentos em conformidade com os três níveis previstos por Slack (1993). 


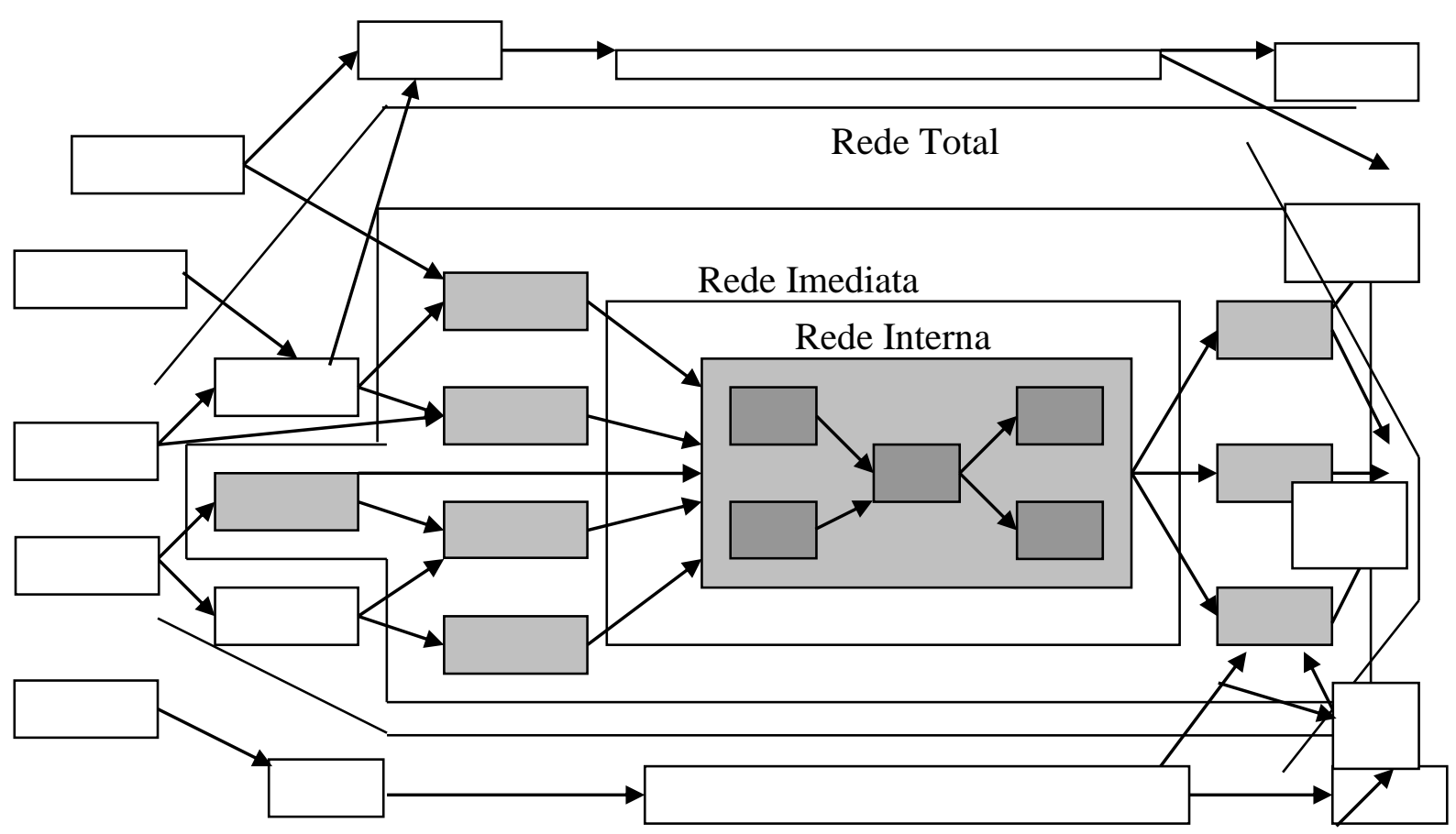

Figura 2 - Níveis das redes de suprimentos

Fonte: Slack (1993, p. 156)

A logística integrada trabalha no atendimento ao fornecedor/empresa/cliente. $\mathrm{Na}$ rede interna estão a empresa e seus departamentos, já a rede imediata abrange fornecedores e clientes, e a rede total é a ligação de todas as imediatas.

A finalidade de toda cadeia de suprimento é maximizar a lucratividade, ou seja, maximizar a diferença entre a receita gerada pelo cliente e o custo total no decorrer da cadeia de suprimento para atender ao seu pedido. Nesse contexto, o resultado de uma cadeia de suprimento deve ser mensurado em termos de lucratividade da cadeia inteira, e não com base nos lucros de um estágio isolado. Chopra e Meindl (2003, p. 6) reconhecem que

todos os fluxos de informação, produtos e fundos geram custos dentro da cadeia. O gerenciamento adequado desses fluxos é a chave para o sucesso da cadeia de suprimento. O gerenciamento da cadeia de suprimento envolve o controle dos fluxos entre os estágios da cadeia para maximizar a lucratividade total. 
Para Ching (1999, p. 68), o desempenho da supply chain depende principalmente de quatro fatores, a saber:

a) capacidade de resposta às demandas dos clientes;

b) qualidade de produtos e serviços;

c) velocidade, qualidade e timing da inovação nos produtos;

d) efetividade dos custos de produção e entrega e utilização de capital.

O correto entendimento e adequado gerenciamento da cadeia de suprimento integrada tem sido considerado fatores de vantagem competitiva para as empresas que efetivamente entendem o seu papel estratégico. Ching (1999, p.68), ao abordar a gestão da cadeia de suprimentos, salienta que

a gestão supply chain se inicia na saída das matérias-primas dos fornecedores. Passa pela produção, montagem e termina na distribuição dos produtos acabados aos clientes finais; formular e implementar estratégias baseadas na retenção dos clientes atuais e obtenção de novos e gerenciar a cadeia de forma eficaz.

A integração interna de uma empresa não é suficiente, pois fazem parte do seu contexto as interações da empresa com seus parceiros, concorrentes, fornecedores e clientes, portanto, a integração externa é indispensável. O gerenciamento da cadeia de suprimento pode representar para a empresa vantagem competitiva em termos de serviço, redução de custo e velocidade de resposta às necessidades do mercado.

\section{MÉTODO E PROCEDIMENTO DA PESQUISA}

Esta pesquisa caracteriza-se como sendo de natureza exploratória e foi realizada por meio de um estudo de caso, com abordagem qualitativa. Para Cervo e Bervian (1996), na pesquisa exploratória se observa, registra, analisa e correlacionam fatos ou fenômenos sem que sejam manipulados. 
O estudo de caso foi intensivo em uma indústria madeireira de Santa Catarina, compreendendo fenômenos inerentes à logística integrada, cuja denominação social declina-se revelar por motivos estratégicos da organização. Yin (2003, p. 21) observa que o estudo de caso permite

uma investigação para se preservar as características holísticas e significativas dos eventos da vida real - tais como ciclos de vida individuais, processos organizacionais, administrativos, mudanças ocorridas em regiões urbanas, relações internacionais e a maturação de alguns setores.

Os dados da pesquisa foram coletados na empresa de duas formas: em arquivos da mesma (pesquisa documental) e por meio da técnica de observação. Fachin (2001, p. 35) denomina a técnica de observação de método observacional e adverte que "o observador deve reunir certas condições, entre as quais dispor dos órgãos sensoriais em perfeito estado, de um bom preparo intelectual, aliado à sagacidade, curiosidade, persistência, perseverança, paciência e um grau elevado de humildade".

No checklist para a coleta de dados foram considerados elementos da logística relacionados aos fornecedores, à empresa em si e aos seus clientes. Para análise dos dados, tanto os de natureza documental (contratos com fornecedores e clientes, laudos técnicos, fichas de produtos, controles de gestão) como os coletados por meio da técnica de observação, utilizou-se a abordagem qualitativa. Richardson (1989, p. 39) explica que "as investigações que se voltam para uma análise qualitativa têm como objeto situações complexas ou estritamente particulares".

Os resultados da pesquisa limitam-se ao caso estudado, uma vez que se escolheu como estratégia de pesquisa estudar somente uma indústria madeireira. Também não foi aplicado um instrumento de pesquisa aos responsáveis pela logística integrada na empresa estudo de caso, restringindo-se à análise documental e técnica de observação. 


\section{DESCRIÇÃO DA LOGÍSTICA INTEGRADA NA INDÚSTRIA MADEIREIRA}

A indústria madeireira estudada possui como atividade econômica a fabricação de portas e móveis. A produção é exclusivamente para exportação. Utiliza toras de pinus para a referida produção, sendo parte da matéria-prima de propriedade da empresa e parte comprada de terceiros. O zelo pela certificação, tanto da empresa como de seus fornecedores, é uma exigência principalmente de seus clientes, o que é comum na exportação de produtos desta natureza.

Por meio da logística integrada a empresa pretende também fazer intervenção na certificação. A empresa precisa analisar para que fim necessita da certificação, pois existem várias modalidades, por exemplo, gestão da qualidade (NBR 9001), gestão ambiental (NBR 14001), gestão da responsabilidade social (NBR 16001), segurança da informação. Seja qual for a modalidade priorizada, ela não é puramente documental. Geralmente faz-se necessária uma reorganização geral da empresa, tanto da empresa fabricante de portas e móveis, como da terceirizada que planta o pinus.

A certificação na indústria madeireira como também dos terceiros que fornecem a matéria-prima (toras de pinus) requer o cumprimento de várias exigências, sejam elas governamentais, de órgãos para-governamentais ou dos clientes. Destacam-se entre as exigências, as que seguem:

a) Canalização de água com tubulação de concreto nas florestas;

b) Largura das estradas dentro de padrão pré-estabelecido pela certificação que se está buscando;

c) Residência dos funcionários na floresta, dentro de padrões pré-estabelecidos;

d) Quando o funcionário não reside, apenas passa o dia na floresta, alimentação em forma de marmitas;

e) Material de segurança adequado para a função à disposição dos funcionários;

f) Não pode haver plásticos, garrafas, outros lixos nas florestas;

g) A semente do pinus deve ser selecionada;

h) O plantio, roçada, desgalhe e desbastes dentro de padrões pré-estabelecidos para portas e móveis; 
i) O corte da tora deve seguir normas também pré-estabelecidas;

j) Necessidade de reflorestamento.

Para obter a certificação leva-se um tempo considerável, pois não bastam documentos que comprovem a melhoria no contexto da empresa; fazem-se necessárias mudanças concretas. Portanto, a indústria madeireira objeto de estudo, assim como seus terceiros, está se utilizando dos recursos do sistema de logística integrada para melhor atender as exigências para certificação da matéria-prima. Com isto também busca obter vantagens competitivas no mercado, por meio da redução de custos, maior agilidade, pontualidade na entrega, qualidade, focalizando a satisfação do cliente.

\subsection{Fornecedores}

$\mathrm{Na}$ perspectiva da logística integrada, vem sendo exigido pela indústria madeireira que seus fornecedores (terceiros) de matéria-prima tenham completa interligação entre as diversas atividades da cadeia, como o suprimento, o planejamento e controle da produção, e dos estoques, bem como o transporte até a indústria madeireira. Isto implica inclusive que os fornecedores ofereçam matéria-prima de melhor qualidade.

Os fornecedores de matéria-prima, neste caso toras de pinos, necessitam enquadrar suas florestas nas normas do selo verde para que possam assim ter seu produto compatível no mercado. Uma vez que o fornecedor tenha a tora certificada, esta é cortada e transportada para o parque fabril da indústria objeto de estudo, sempre considerando as necessidades de fornecimento da cadeia completa.

O serviço logístico do fornecedor é medido, conforme preconizado por Bowersox e Closs (2001), em termos de: disponibilidade, desempenho operacional e confiabilidade de serviço. A disponibilidade diz respeito ao estoque mantido na empresa, o que não quer dizer níveis elevados de estoque ou estoque zero, mas o gerenciamento para evitar excesso ou falta de estoque. $O$ desempenho operacional compreende o intervalo de tempo entre o recebimento do pedido e a entrega da mercadoria, portanto, relaciona a velocidade e consistência da entrega, bem como a 
flexibilidade no atendimento de pedidos inesperados e o atendimento ao cliente após a entrega realizada. A confiabilidade do serviço consiste no equilíbrio entre a disponibilidade do estoque e o desempenho operacional.

\subsection{Empresa}

A logística integrada vem sendo implantada na referida indústria madeireira visando melhor atendimento ao cliente, melhorando seu parque fabril, principalmente para o funcionamento integrado e eficaz do complexo processo de industrialização de seus produtos, assim como melhoria na qualidade do produto e agilidade na sua entrega.

Com o sistema de logística integrada a indústria tem maior precisão na entrega do produto ao cliente final. Para um melhor funcionamento da logística integrada a empresa objeto de estudo teve que reestruturar e formalizar seus processos internos, no sentido de melhor integrar os fornecedores e clientes. Na Figura 3 se apresenta o sistema de logística integrada da empresa na perspectiva interna. 


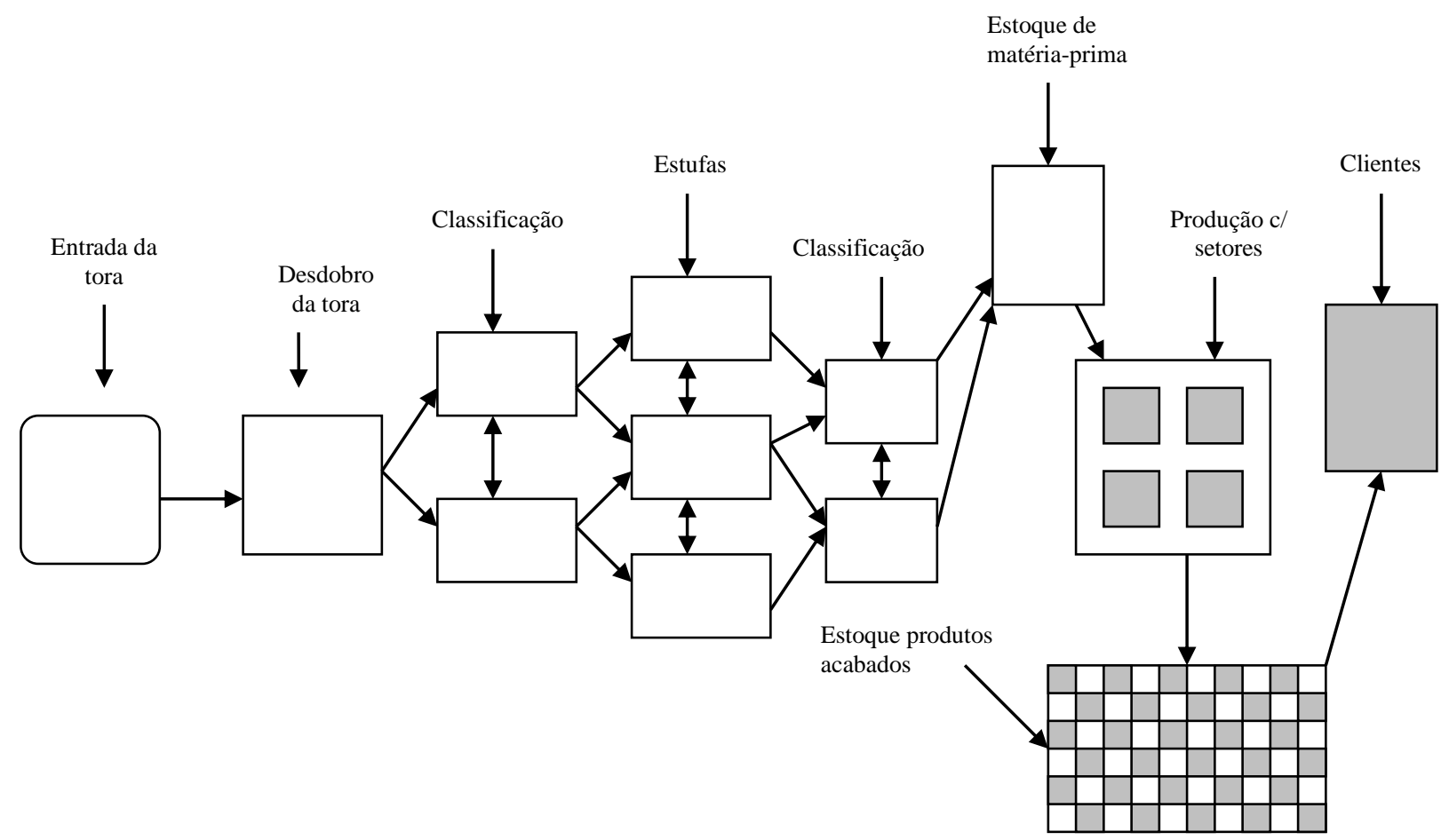

Figura 3 - Sistema de logística integrada na indústria

Fonte: Elaborado pelas autoras

O sistema de logística integrada acontece também dentro da indústria madeireira objeto de estudo e funciona conforme demonstrado na Figura 3. Quando a tora chega na empresa esta é certificada, verificando se está dentro dos padrões estabelecidos. A partir daí começa o desdobramento da tora em tábuas de várias espessuras.

As tábuas cortadas são empacotadas não se observando a espessura, e encaminhadas às estufas onde ficam em média 72 horas. Em seguida são classificadas conforme sua espessura e armazenadas em pallets. Com uma codificação interna da empresa, aguardam a solicitação da produção das portas e móveis.

Quando a produção necessita de um determinado tipo de madeira (matéria-prima serrada), o pedido é feito via sistema. Ele identifica onde está armazenada a matériaprima e emite autorização da retirada do pallet com a madeira. Também já emite um aviso à produção de matéria-prima toras da necessidade de reposição da matéria-prima serrada, que acaba de ser utilizada.

Chegando a madeira no setor solicitado, são produzidos os moldes vendidos. Quando o produto está pronto, este é embalado e identificado por uma etiqueta com 
código de barras. Neste código estão descritas, entre outras informações, a procedência da matéria-prima e dos materiais secundários utilizados na sua fabricação. O produto, então, é levado por um transelevador e armazenado em prateleiras de logística, pois quando o cliente faz um pedido é possível ver se a empresa possui o material para entrega imediata.

A logística é aplicada também aos subprodutos armazenados na indústria madeireira. Estes são resultantes da fabricação dos produtos principais, portas e móveis como, por exemplo, o flat jamb (união de vários pedaços de madeiras colados entre si e prensados, que têm usinadas as faces e, em seguida, são efetuados rebaixes e encaixes nas madeiras. É utilizado para vista lateral de porta, ou seja, um montante mais estreito) e o montante (união de vários pedaços de madeiras colados entre si e prensados em máquina própria denominada prensa).

Infere-se do exposto que a indústria madeireira pesquisada já possui algumas etapas implantadas do sistema de logística integrada, especialmente nos seus processos internos. Precisa ainda reestruturar seu relacionamento com fornecedores e clientes. Com isso pretende triplicar a produção, buscando diminuir custos com mão-deobra, perda de tempo, dentre outros aspectos de melhoria da qualidade.

\subsection{Clientes}

Com o produto acabado armazenado em prateleiras logísticas (prateleiras que armazenam o produto com a respectiva identificação, desde a origem da matéria-prima até seu completo processamento, com dados registrados no sistema de informação logística para fácil localização), a indústria madeireira consegue informar imediatamente ao cliente a possibilidade de atendimento de seu pedido. Também pode ser informado com precisão o prazo de entrega e a forma como será encaminhado o produto acabado ao cliente, entre outros aspectos relacionados à exportação que precisam ser providenciados.

Depreende-se que a logística possibilita atender às necessidades dos clientes de maneira rápida, sem que ocorram problemas com falta de produtos no estoque. Também busca atender a integralização das normas do selo verde, tanto na indústria 
madeireira em questão, como junto a terceiros, o que permite que o cliente fique mais seguro na aquisição do seu produto, pois o produto é certificado desde o fornecedor da matéria-prima até completar a cadeia total.

O serviço prestado ao cliente é examinado nas três dimensões previstas por Christopher (1997), como segue: elementos de pré-transação, da transação e da póstransação. Os elementos da pré-transação caracterizam-se pelo acesso do cliente ao produto (política formal de serviço ao cliente, flexibilidade do sistema). Os elementos da transação correspondem à disponibilidade do produto (ciclo do pedido, informações sobre a posição do pedido). Os elementos da pós-transação referem-se ao fator pósvenda (reposição do produto, assistência técnica).

\section{CONCLUSÃO}

O presente artigo objetivou descrever a logística integrada em uma indústria madeireira de Santa Catarina. Para tanto, foi realizada uma pesquisa exploratória, por meio de estudo de caso com abordagem qualitativa. Os dados foram coletados em arquivos da empresa, constituindo-se em análise documental, e por meio da técnica de observação. No checklist foram considerados elementos da logística integrada na perspectiva fornecedores-empresa-clientes.

Os resultados da pesquisa mostram que a indústria madeireira está buscando, na aplicação de um sistema de logística integrado próprio e com seus fornecedores (terceiros) de matéria-prima (toras de pinus), a dinâmica das necessidades do consumidor e da tecnologia, garantindo assim confiabilidade nos produtos e processos, além de atender às expectativas dos clientes.

A logística integrada na indústria madeireira busca sincronizar os setores de produção (internamente), se estendendo para trás, exigindo dos seus fornecedores (terceiros) da matéria-prima (toras de pinus) maior qualidade, certificação de suas florestas, assim como pontualidade na entrega da matéria-prima em questão; e para frente, com seus clientes, visando melhor atendimento, agilidade na entrega e 
qualidade do produto. Este sincronismo vem sendo implantado de forma gradual, mas vislumbrando a total integração de fornecedores e clientes à empresa.

$\mathrm{Na}$ indústria madeireira a logística integrada está sendo implantada de maneira lenta, porém com resultados interessantes, tais como: a) a empresa está se modernizando internamente, no seu parque fabril; b) a empresa está cobrando de seus fornecedores a necessidade de melhorar a qualidade da matéria-prima, como também maior pontualidade na entrega; e, c) a empresa busca a melhoria no atendimento ao cliente e com maior agilidade.

A logística integrada mostra-se relevante na indústria madeireira pesquisada, uma vez que contribui para conferir maior qualidade ao produto que fabrica, devido ao fato de existir integração efetiva entre todos os setores. Os fornecedores, utilizando-se da logística integrada, tendem a primar pela qualidade da matéria-prima que vendem, bem como conferir maior satisfação ao cliente final, o que decorre dos laços estreitos entre ambos.

Destaca-se, também, que a logística integrada está proporcionando à cadeia global da indústria madeireira a redução de custos e maior agilidade no atendimento, além de maior satisfação aos clientes ao longo do processo. Com efeito, constataramse ganhos de competitividade por ter dentre vários diferenciais a logística integrada entre fornecedores-empresa-clientes, o que proporciona resultados favoráveis a todos os integrantes da cadeia.

Como os achados da pesquisa limitam-se à indústria madeireira objeto de estudo, recomenda-se que pesquisa semelhante seja realizada em outras empresas do mesmo setor, a fim de comparar os resultados. Também se recomenda a utilização de outras estratégias de pesquisa para confirmar os resultados aqui encontrados como, por exemplo, a aplicação de um roteiro de entrevista aos responsáveis pela logística integrada de cada etapa da cadeia de valor completa.

\section{REFERÊNCIAS}

BALLOU, R. H. (1993). Logística empresarial: transportes, administração de materiais, distribuição física. São Paulo: Atlas, 388 p. 
BOWERSOX, Donald J.; CLOSS, David J. (2001). Logística empresarial: o processo de integração da cadeia de suprimento. São Paulo: Atlas, 594 p.

BOWERSOX, Donald J.; CLOSS, David J.; COOPER, M.B. (2006). Gestão logística de cadeias de suprimentos. Porto Alegre: Bookman.

CERVO, Amado Luiz; BERVIAN, Pedro Alcino. (1996). Metodologia científica. (4 ed.). São Paulo: Makron Books, 249 p.

CHING, Hong Yuh. (1999). Gestão de estoques na cadeia de logística integrada. São Paulo: Atlas, $179 \mathrm{p}$.

CHOPRA, Sunil; MEINDL, Peter. (2003). Gerenciamento da cadeia de suprimentos: estratégia, planejamento e operações. São Paulo: Prentice Hall, 465 p.

CHRISTOPHER, Martin. (1997). Logística e gerenciamento da cadeia de suprimentos: estratégias para a redução de custos e melhoria dos serviços. São Paulo: Pioneira, 240 p.

DORNIER, Philippe-Pierre et al. (2000). Logística e operações globais: texto e casos. São Paulo: Atlas, 721 p.

FACHIN, Odília. (2001). Fundamentos de metodologia. São Paulo: Saraiva, 200 p.

HOEK, Remko Van; HARRISON, Alan. (2003). Estratégia e gerenciamento de logística. São Paulo: Futura, 248 p.

LADEIRA, Marcelo Bronzo; OLIVEIRA, Marcos Paulo Valadares. (2007). A influência do planejamento e das capacidades logísticas sobre o desempenho dos ciclos de valor da logística integrada. In: ENANPAD, 31. Rio de Janeiro. Anais ... Rio de Janeiro: ANPAD. CD-ROM.

NOHARA, Jouliana Jordan; ACEREDO, Claudia Rosa. (2005). Gerenciamento de cadeia de suprimentos: conceitos e desafios na implantação. In: ENANPAD, 29., Brasilia/DF. Anais... Rio de Janeiro: ANPAD. CD-ROM.

NOVAES, Antônio Galvão. (2004). Logística e gerenciamento da cadeia de distribuição: estratégia, operação e avaliação. (2 ed.). Rio de Janeiro: Elsevier, 408 p.

PIRES, Sílvio R. I. (2004). Gestão da cadeia de suprimentos: conceitos, estratégias, práticas e casos. São Paulo: Atlas, $310 \mathrm{p}$.

RICHARDSON, Roberto Jarry. (1989). Pesquisa social: métodos e técnicas. Colaboradores Jose Augusto de Souza Peres, et al., (2 ed.). São Paulo: Atlas, 286 p. 
SILVA, Liane Márcia Freitas; VILLAR, Antonio de Mello. (2007). Discussão sobre as técnicas de avaliação dos custos logísticos para fins de controle gerencial. In: Congresso Brasileiro de Custos, 14. João Pessoa, 2007. Anais... São Leopoldo: ABC. CD-ROM.

SLACK, Nigel. (1993). Vantagem competitiva em manufatura: atingindo competitividade nas operações industriais. São Paulo: Atlas, 198 p.

SLACK, Nigel et al. (1996). Administração da produção. São Paulo: Atlas, 726 p.

VEROL, Marcus; DALTO, Edson. (2007). Estratégias logísticas nas empresas de telefonia celular: status e oportunidades na gestão de aparelhos. In: SIMPOI, 10. São Paulo. Anais ... São Paulo: FGV. CD-ROM.

YIN, Robert K. (2003). Estudo de caso: planejamento e métodos. São Paulo, Bookman, $205 \mathrm{p}$.

Data de Submissão: 28/05/2008

Data de Aceite: 02/07/2008 